\begin{tabular}{c|c|c}
\hline & MARINE ECOLOGY PROGRESS SERIES \\
Vol. 273: 281-289, 2004 & Mar Ecol Prog Ser & Published June 8 \\
\hline \hline
\end{tabular}

\title{
Non-linear dynamics in marine-phytoplankton population systems
}

\author{
Andrea Belgrano ${ }^{1,5, *}$, Mauricio Lima ${ }^{2}$, Nils C. Stenseth ${ }^{3,4}$ \\ ${ }^{1}$ Department of Biology, University of New Mexico, 167 Castetter Hall, Albuquerque, New Mexico 87131-1091, USA \\ ${ }^{2}$ Center for Advanced Studies in Ecology \& Biodiversity, Pontificia Universidad Católica de Chile, PO Box 114-D, \\ Santiago 6513677, Chile \\ ${ }^{3}$ Centre for Ecological and Evolutionary Synthesis (CEES), Department of Biology, University of Oslo, \\ PO Box 1050 Blindern, 0316 Oslo, Norway \\ ${ }^{4}$ Institute of Marine Research, Flødevigen Marine Research Station, 4817 His, Norway
}

${ }^{5}$ Present address: National Center for Genome Resources (NCGR), 2935 Rodeo Park Drive East, Santa Fe, New Mexico 87505, USA

\begin{abstract}
Although non-linear density-dependence has been widely emphasized in population dynamics studies, the existence of non-linear exogenous forces have been less explored. In particular, we propose that the formulation of population dynamics models that include both non-linear endogenous (i.e. feedback structure) and exogenous (e.g. climatic) responses is relevant for understanding how climate variability affects natural systems. Here we show that single-species non-linear logistic models for marine phytoplankton in combination with non-linear exogenous forces capture observed population oscillations very well. Our results suggest that general population dynamic theory represents a useful tool for understanding the natural fluctuations of phytoplankton populations. Altogether we document what might be called a switch-on/switch-off dynamics in the phytoplankton population dynamics in relation to climate variability. We suggest the importance of, and the need for, linking population dynamics processes at local and regional scales to processes at the ecosystem level, thus reflecting a macroecological perspective of marine pelagic systems.
\end{abstract}

KEY WORDS: Phytoplankton populations - North Atlantic Oscillation - Non-linear dynamics · Density-dependence $\cdot$ Macroecology

Resale or republication not permitted without written consent of the publisher

\section{INTRODUCTION}

A central goal in population ecology is to understand the mechanisms underlying the numerical fluctuations of natural populations (Royama 1992, Murdoch et al. 2002) and, as part of that, to better understand how changes in population dynamics may be understood as the result of a combination of exogenous and endogenous factors (Turchin 1995, Hanski 1999). Endogenous factors represent the feedback loops created by individual interactions (within and between populations), while exogenous factors represent forcing variables which influence population changes, but they are not influenced back by the population state (Berryman 1981, 1999). In fact, nowadays most population ecolo- gists agree that both factors are operating (Turchin 1995); however, the complex combination of exogenous and endogenous forces in ecological populations makes the study of their dynamics a conceptual and methodological challenge (Bjørnstad \& Grenfell 2001). Recent studies have emphasized the implications of non-linearity in the feedback structure (Stenseth et al. 1997, Bjørnstad et al. 1998, 1999, Berryman 1999, Kristoffersen et al. 2001), while others have focused on the role of climatic forcing in ecological dynamics (Merritt et al. 2001, Mysterud et al. 2001, Stenseth et al. 2002, 2003). One interesting aspect about nonlinearity is that the shape of the density-dependent function (feedback structure) may be an important clue in understanding what factors determine popula- 
tion growth rates (Berryman 1999, Sinclair \& Krebs 2002). Moreover, determining the feedback structure is an essential step for understanding population responses to climatic variability, and how exogenous perturbations (e.g. climate) influence population processes (Royama 1992, Stenseth et al. 2002). On the other hand, the existence of non-linearity in climatic forcing has been recently explored in terrestrial (Murúa et al. 2003) and marine ecosystems (L. Ciannelli et al. unpubl.).

Although phytoplankton fluctuations have not been analyzed previously using population dynamic theory, there are a number of studies showing the role of oceanographic and climatic factors in determining algal blooms and dynamics (Reid et al. 1998, Belgrano et al. 1999). On the other hand, a recent study (Smayda 2002) showed very clearly the comparison between the ecological strategies of diatoms and dinoflagellates, describing population dynamics patterns such as growth, colonization and extinction. In a more theoretical framework, Chesson \& Huntly (1997), Chesson (2000), and Anderies \& Beisner (2000) described species coexistence and species interactions in fluctuating environmental conditions such as disturbance, seasonality and weather variability in order to understand some of the mechanisms regulating species diversity at a community level. Although phytoplankton fluctuations may be related to an array of limiting resources and oceanographic and climatic variables (Huisman \& Weissing 1999), for planktonic systems it has generally been shown that it is important to consider non-equilibrium resource supply coupled with physical forcing and fluctuating light (Armstrong \& McGehee 1976, Litchman \& Klausmeier 2001).

In this study we use the classical framework of population dynamics theory (feedback structure = density-dependence and exogenous forces = densityindependence) when modeling marine phytoplankton populations. We used non-parametric regression models to analyze the dynamics of 3 phytoplankton species in a Swedish fjord. Our aim was to determine the existence of non-linearity in the density-dependent structure and in the climate forcing terms in order to explain the numerical fluctuations exhibited by these marine phytoplankton populations during $11 \mathrm{yr}$ of study.

\section{MATERIALS AND METHODS}

Phytoplankton and environmental data. The data used in this study consist of phytoplankton species (cell counts) and abiotic factors measured on a monthly basis using a conductivity-temperature-depth (CTD) probe (GO MARK IIIC, General Oceanics) at hydrographic standard depths and analyzed accord- ing to the Swedish standard method (SIS) as reported in Belgrano et al. (1999). The station was located at the mouth of the Gullmar fjord on the Swedish west coast ( $58^{\circ} 15^{\prime} \mathrm{N}, 11^{\circ} 26^{\prime}$ E) (Fig. 1). Phytoplankton were monitored monthly from 1986 to 1996; samples collected at sea from the surface to $20 \mathrm{~m}$ depth at intervals of $5 \mathrm{~m}$ were fixed using Lugol's (acid-iodine) and concentrated through sedimentation cylinders (10 to $50 \mathrm{ml}$ ) of combined plate counting chambers (Belgrano et al. 1999). The counting procedure was performed according to HELCOM (1988) using an inverted microscope at 3 magnifications $(\times 10, \times 20$ and $\times 40$ ) with a $\times 10$ ocular magnification. Three species were selected from a 40 species database: Skeletonema costatum (diatom), Ceratium tripos and $C$. furca (dinoflagellates) were chosen to study in more detail their dynamics in relation to the North Atlantic Oscillation (NAO) and a suite of abiotic factors (these variables were chosen based on previous work reported in Belgrano et al. 2001), and are listed in Table 1. The wind speed of the 4 quadrants (NE, SE, SW and NW) was measured every third hour at the national weather station Måseskär, which measures wind conditions along the outer archipelago and in the mouth area of the Gullmar fjord (Lindahl et al. 1998). The index of the NAO was provided online (available at www.cgd.ucar.edu/ jhurrell/nao.html) and as reported by Hurrell (1995).

It is important to note the correlation between environmental variables, e.g. salinity and density were highly positively correlated (Pearson's correlation coefficient $r=0.91$ ), and wind intensity also showed

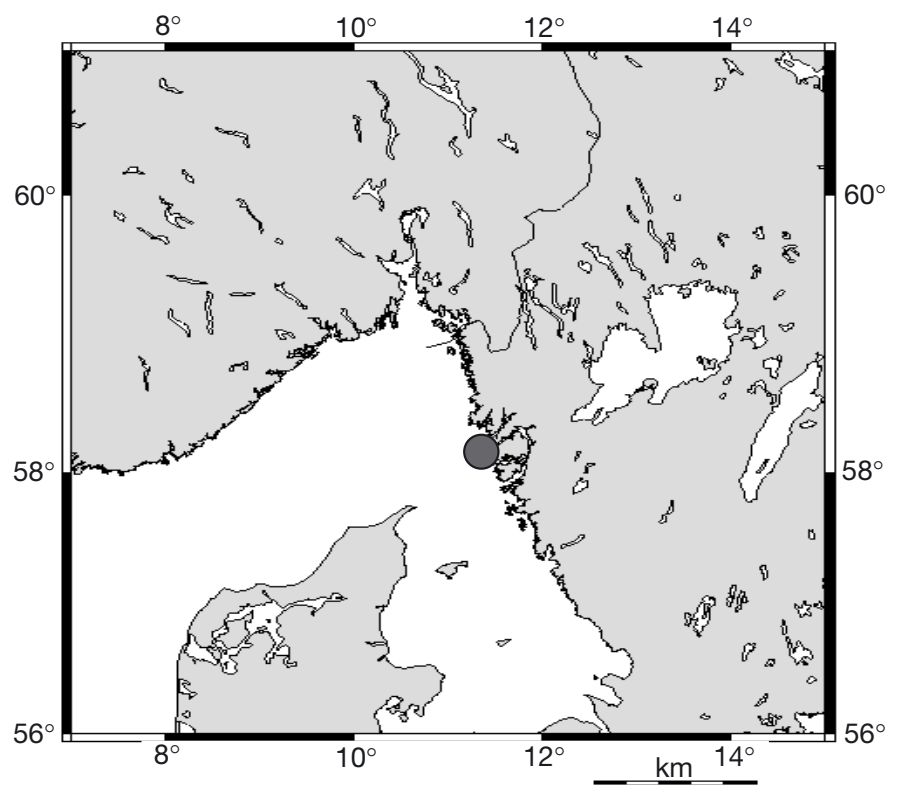

Fig. 1. Study area. The station was located at the mouth of the Gullmar Fjord on the Swedish west coast $\left(58^{\circ} 15^{\prime} \mathrm{N}, 11^{\circ} 26^{\prime} \mathrm{E}\right)$ 
Table 1. List of the abiotic variables used as input for the models. NAO: North Atlantic Oscillation

\begin{tabular}{|ll|}
\hline Input variable & Unit \\
\hline $\mathrm{Chl} \mathrm{a}$ & $\mu \mathrm{g} \mathrm{l}^{-1}$ \\
$\mathrm{PO}_{4}{ }^{3-}$ & $\mu \mathrm{mol} \mathrm{l}^{-1}$ \\
$\mathrm{NO}_{3}{ }^{-}$ & $\mu \mathrm{mol} \mathrm{l}{ }^{-1}$ \\
$\mathrm{NAO}$ & $\mathrm{Index}$ \\
Temperature & ${ }^{\circ} \mathrm{C}$ \\
Salinity & $\mathrm{PSU}$ \\
Density & $\sigma_{\mathrm{t}}$ \\
$\mathrm{NE}$ wind & $\mathrm{m} \mathrm{s}^{-1}$ \\
$\mathrm{NW}$ wind & $\mathrm{m} \mathrm{s}^{-1}$ \\
SW wind & $\mathrm{m} \mathrm{s}^{-1}$ \\
SE wind & $\mathrm{m} \mathrm{s}^{-1}$ \\
\hline
\end{tabular}

positive correlations between southwest and southeast winds (Pearson's correlation coefficient $r=0.63$ ), southwest and northwest winds (Pearson's correlation coefficient $r=0.67$ ), and southeast and northwest winds (Pearson's correlation coefficient $r=0.47$ ).

The 3 species were selected in order to compare the variability of a common diatom Skeletonema costatum that comprised a very large bloom in the Swedish coastal waters in 1987, and 2 species of dinoflagellates, Ceratium tripos and C. furca, since an increase in their abundance may indicate a shift in the phytoplankton assemblages from larger to smaller cell sizes. Ultimately, since dinoflagellates possess different ecological adaptations to diatoms (Smayda 2002), we were interested in understanding some of the mechanisms underlying their population dynamics, in particular by comparing organisms exhibiting predictable behavior (diatoms) to those with unpredictable behaviour (dinoflagellates).

The underlying population dynamics model for these 3 species may be represented by the general model in terms of the density-dependence and density-independence in the reproduction and survival of individuals (Berryman 1999), leading to a generalized Ricker discrete-time logistic model (Ricker 1954), influenced by climate and stochastic forces:

$$
\left.N_{t}=N_{t-1} \times \mathrm{e}^{\left[a_{N}+f_{1}\left(N_{t-1}\right)+\sum_{1}^{i=k} g^{i}\left(C_{t}^{i}\right)+\varepsilon_{t}\right.}\right]
$$

where $N_{t}$ is phytoplankton abundance at time $t$ (in months), $C$ is the exogenous variable, and $\varepsilon_{t}$ represents normally distributed stochastic perturbations.

The function $f\left(N_{t-1}\right)$ represents the effects of withinpopulation ecological interactions; $g^{i}$ represents the exogenous force, e.g. direct effects of oceanographic (salinity) and climatic (winds) conditions, or nutrients (nitrate) on phytoplankton population dynamics. An alternative way to express Eq. (1) is in terms of the realized per-capita population growth rates or the $\mathrm{R}$ - function, which represents the processes of individual survival and reproduction driving population dynamics and can be defined as $R_{t}=\log _{\mathrm{e}}\left(N_{t}\right)-\log _{\mathrm{e}}\left(N_{t-1}\right)$; thus, Eq. (1) may be expressed as the following R-function (Berryman 1999):

$$
R_{t}=a_{N}+f_{1}\left(N_{t-1}\right)+\sum_{1}^{i=k} g^{i}\left(C_{t}^{i}\right)+\varepsilon_{t}
$$

This model represents the basic feedback structure and integrates the exogenous and stochastic forces that drive population dynamics in nature. In order to represent the functions we may choose a family of functional form. Hence, our model is an additive non-linear model (see Bjørnstad et al. 1998 for an ecological example), or a generalized additive model (GAM) (Hastie \& Tibshirani 1990). The choice of the functional form of the non-linear functions may be approached using natural cubic splines (Green \& Silvermann 1994, Stenseth et al. 1997, Bjørnstad et al. 1998). The complexity of the function (i.e. the number of degrees of freedom) and the number of terms was estimated using penalized regression splines and generalized cross validation (GCV) (Wood 2001). Smoothing terms are estimated using penalized regression splines with smoothing parameters selected by GCV. In general, the most logically consistent method to use for deciding which terms to include in the model is to compare GCV scores for models with and without the term. More generally, the score for the model with a smooth term can be compared to the score for the model with the smooth term replaced by appropriate parametric terms. Candidates for replacement by parametric terms are smooth terms with estimated degrees of freedom close to their minimum possible (1 degree of freedom). This statistical modeling approach may then be used in order to determine the climatic influences and the density-dependence structure. The models were implemented using S-Plus (2000).

\section{RESULTS}

The 3 phytoplankton species showed large fluctuations in cell density during the study period (Fig. 2). In the case of marine phytoplankton populations, there are strong seasonal dynamics characterized by the fact that, in winter, phytoplankton species are often not present in the water column. To avoid the problem caused by presence/absence data, we eliminated the zero values from the series: only data with positive values were analyzed. After eliminating the zero values, the realized per capita population growth rates in the 3 species showed a negative relationship with population density (Fig. 3), suggesting that these phytoplankton populations may be characterized by first order negative feedback (i.e. direct density-dependence). 

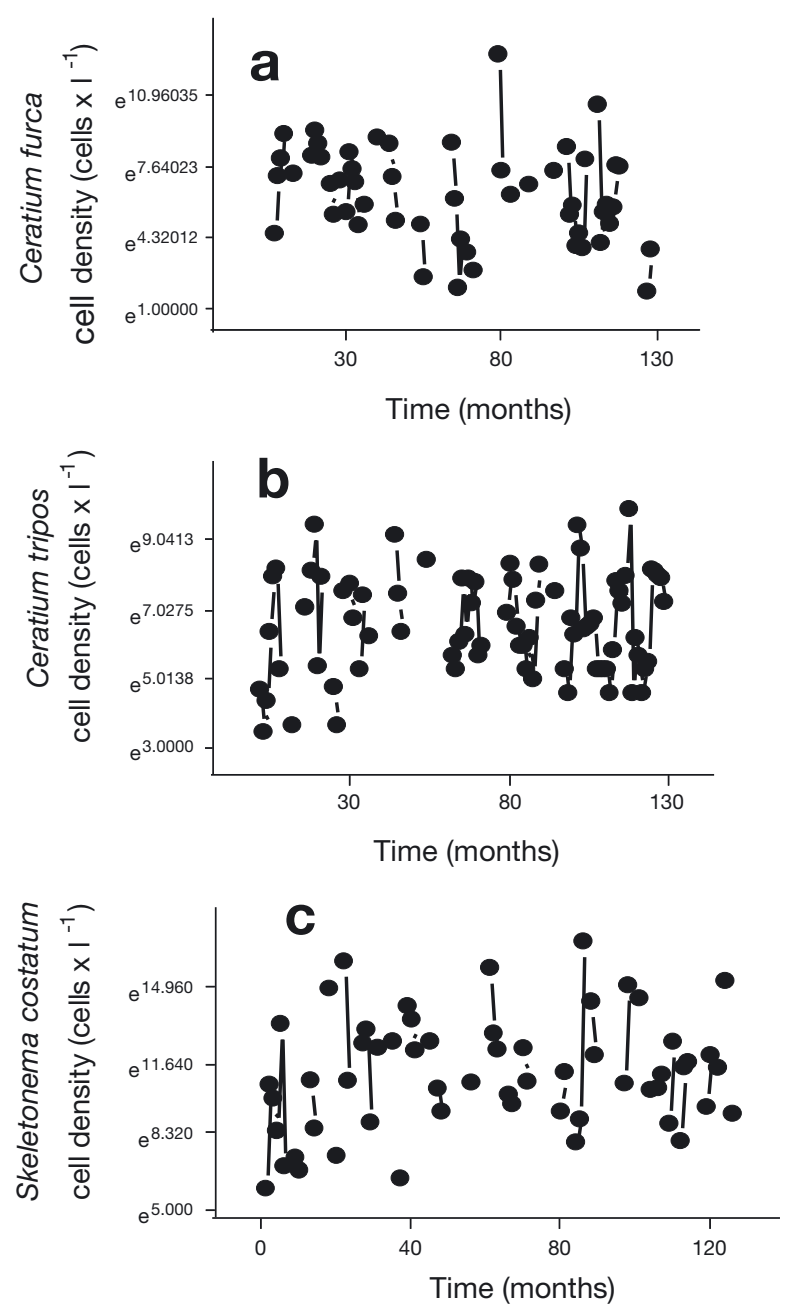

Fig. 2. Temporal dynamics of (a) Ceratium furca, (b) C. tripos, and (c) Skeletonema costatum. Phytoplankton population density is expressed as number of cells $\mathrm{l}^{-1}$, missing points correspond to those months with no phytoplankton cells in the column of seawater

The model obtained for the dinoflagellate Ceratium furca (Fig. 4) showed a weak non-linear negative firstorder feedback structure, non-linear positive effects of the NAO, negative non-linear effects of the seawater density and negative non-linear effects of northeast wind intensity (Fig. 4, Tables 2 \& 3). This model accounts for $89 \%$ of the variance (Table 2). The model obtained for C. tripos (Fig. 5) clearly suggests a loglinear negative first-order feedback, a positive nonlinear effect on temperature, non-monotonic effects of northeast wind intensity, a positive non-linear effect of NAO and nitrates, and negative non-linear effect of southeast wind intensity and salinity (Fig. 5, Tables 2 \& 3). The model accounts for $90 \%$ of the variance.

The diatom Skeletonema costatum (Fig. 6) exhibits log-linear first-order feedback, a non-monotonic effect

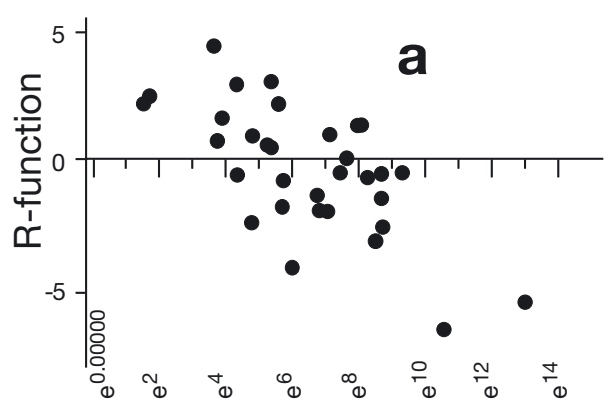

Cell density (number of cells/l)

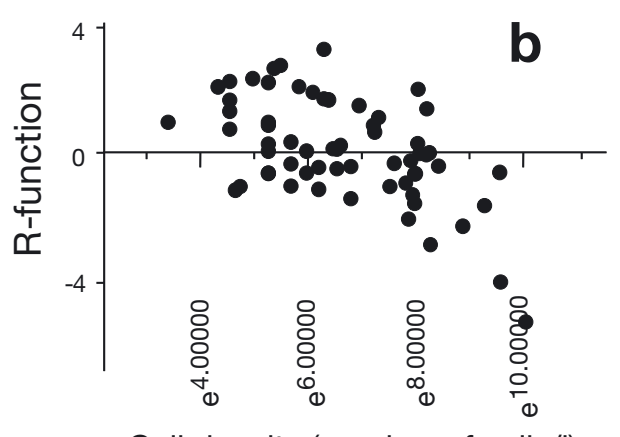

Cell density (number of cells/l)

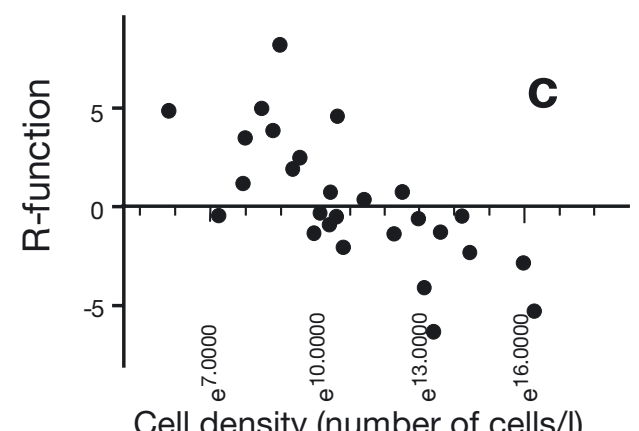

Cell density (number of cells/l)

Fig. 3. R-functions (per capita growth rates estimated as $\ln N_{t}-\ln N_{t-1}$ ) against population density for (a) C. furca, (b) C. tripos and (c) S. costatum

of southwest wind intensity, non-linear positive effect of temperature and non-linear positive effect of northeast wind intensity; in addition we determined a linear positive effect of nitrates and a negative effect of salinity (Fig. 6, Tables $2 \& 3$ ). The model for S. costatum including the covariates accounts for $97 \%$ of the observed variance.

\section{DISCUSSION}

Population dynamics of these phytoplankton species are governed by endogenous and exogenous factors 

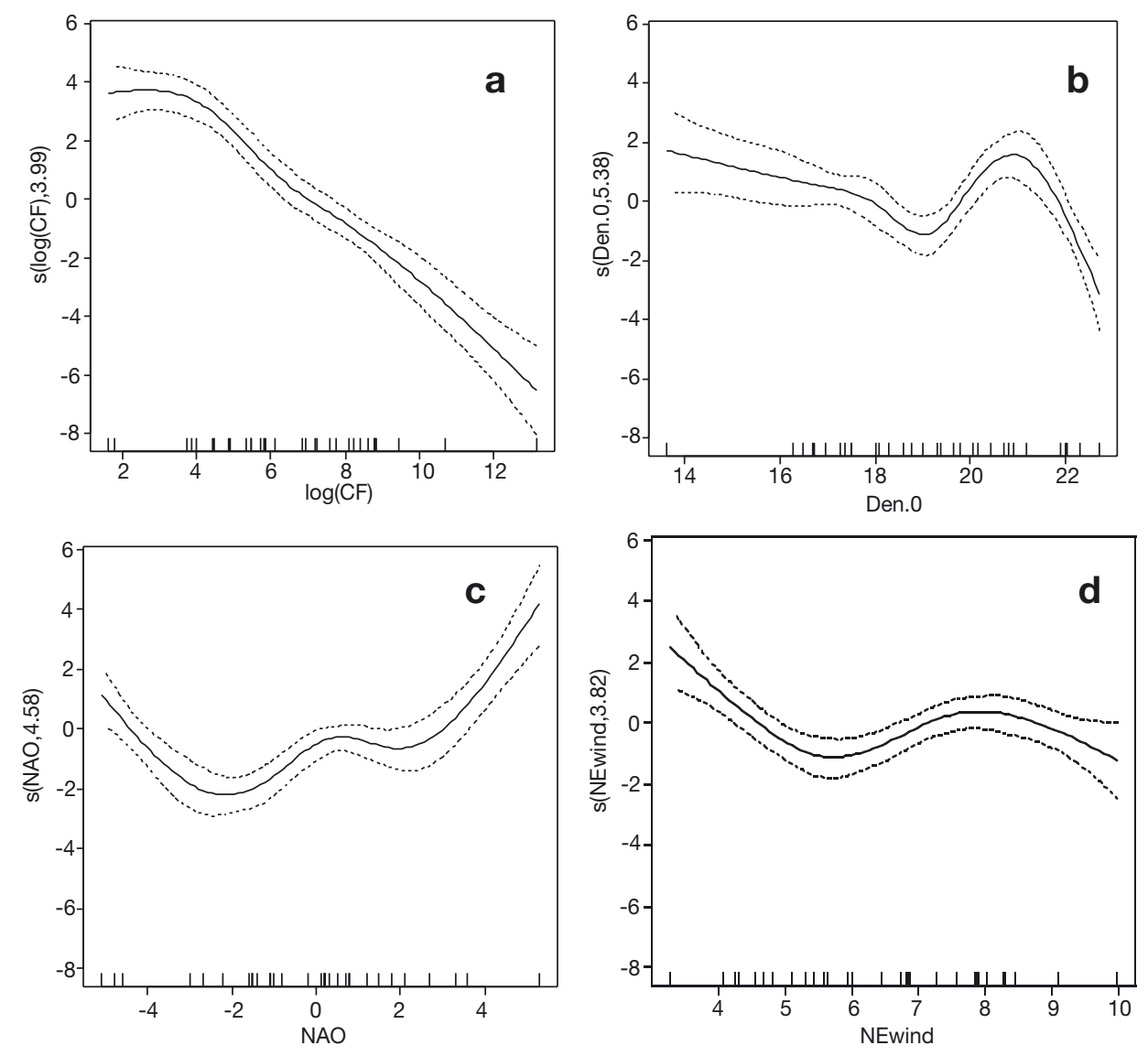

Fig. 4. Partial residuals of the nonlinear terms estimated by means of generalized additive models (GAM) with smoothing splines. The appropriate smoothness for each applicable model term was selected using generalized cross validation (GCV). We used a GAM model for determining nonlinear effects on population growth rates of Ceratium furca, the independent variables showing non-linearity were: $C$. furca density $(\mathrm{CF})$; density of seawater (Den.0); North Atlantic Oscillation index (NAO); and northeast wind intensity (NEwind). Tick marks on $x$-axis show the locations of the observations on each variable
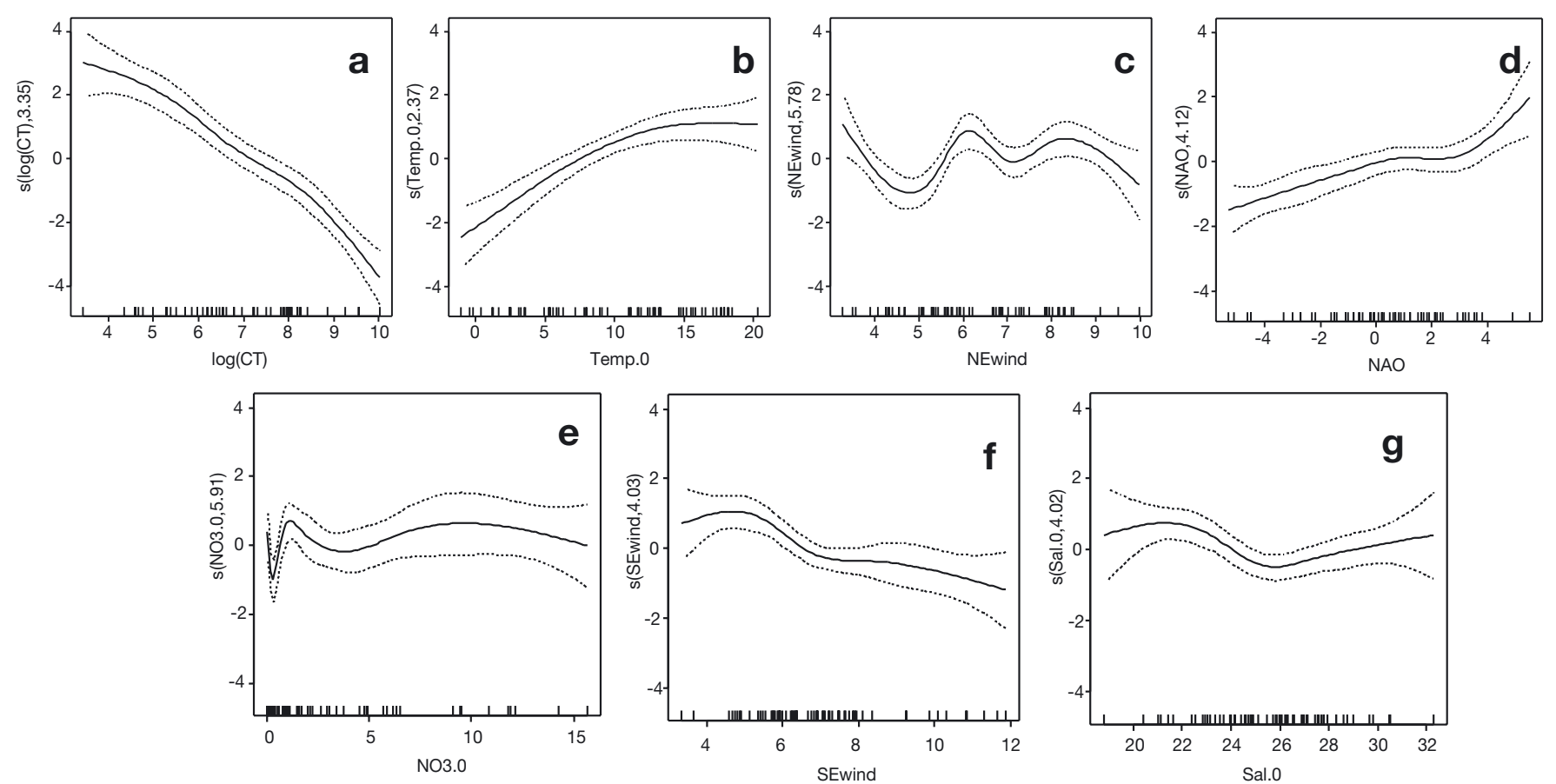

Fig. 5. Ceratium tripos. See legend to Fig. 4 for details. C. tripos density (CT); temperature (Temp.0); northeast wind (NEwind); north Atlantic Oscillation (NAO); nitrate $\left(\mathrm{NO}_{3} .0\right)$; southeastern wind intensity (SEwind); and salinity (Sal.0) are shown 
Table 2. Best population dynamic models for each phytoplankton species. Incorporation of all variables produces a large number of possible models. We present only the statistically optimal models, chosen by Schwarz's Bayesian criterion (SBC) (S-Plus 2000). SBC is obtained as $-2 \times \log$-likelihood + npar $\times \log$ (nobs), where npar and nobs represent number of parameters and observations in the fitted model, respectively. Model parameters were estimated by regression analysis in R-project software. Most parsimonious models according to Bayesian Information Criterion ( $\triangle \mathrm{BIC}>2$ is considered significant) are chosen and denoted in bold. $\mathrm{p}=$ probability value, $\mathrm{R}^{2}=$ coefficient of determination, $\mathrm{BIC}=\mathrm{BIC}$ criterion value, $\Delta \mathrm{BIC}$ is the difference in Schwarz's Bayesian criterion (SBC) from the most parsimonious model. Model notations are: $N_{t-1}=$ phytoplankton density or abundance, $\mathrm{NAO}=$ North Atlantic Oscillation index, $\mathrm{NO}_{3}=$ nitrate, $\mathrm{PO}_{4}=$ phosphate, Temp $=$ temperature, Sal $=$ salinity, Den $=$ density of seawater, SEwind = southeast wind, NEwind = northeast wind, SWwind = southwest wind and NWwind = northwest wind

\begin{tabular}{|c|c|c|c|c|c|}
\hline & $F_{\mathrm{df}}$ & $\mathrm{p}$ & $\mathrm{R}^{2}$ & BIC & $\triangle \mathrm{BIC}$ \\
\hline \multicolumn{6}{|l|}{ Ceratium furca models } \\
\hline$R_{t}=f_{1}\left(N_{t-1}\right)+f_{2}(\mathrm{NAO})+f_{3}(\mathrm{Den})$ & $10.03(13,16)$ & 0.00002 & 0.89 & 117.90 & $\mathbf{0 . 0 0}$ \\
\hline$R_{t}=f_{1}\left(N_{t-1}\right)+f_{2}(\mathrm{NAO})+f_{3}(\mathrm{Den})+f_{4}(\mathrm{SWwind})$ & $8.95(12,17)$ & 0.00004 & 0.90 & 121.22 & 40.83 \\
\hline$R_{t}=f_{1}\left(N_{t-1}\right)+f_{2}(\mathrm{NAO})+f_{3}(\mathrm{Den})+f_{4}\left(\mathrm{PO}_{4}\right)+f_{5}(\mathrm{SWwind})$ & $7.54(15,14)$ & 0.0003 & 0.89 & 124.96 & 44.55 \\
\hline$R_{t}=f_{1}\left(N_{t-1}\right)+f_{2}(\mathrm{NAO})+f_{3}(\mathrm{Den})+f_{4}\left(\mathrm{NO}_{3}\right)+f_{5}(\mathrm{SWwind})$ & $7.08(15,14)$ & 0.0004 & 0.88 & 126.61 & 49.96 \\
\hline$R_{t}=f_{1}\left(N_{t-1}\right)+f_{2}(\mathrm{NAO})+f_{3}(\mathrm{Sal})+f_{4}(\mathrm{SWwind})$ & $6.68(12,17)$ & 0.0003 & 0.83 & 128.62 & 57.36 \\
\hline$R_{t}=f_{1}\left(N_{t-1}\right)+f_{2}(\mathrm{NAO})+f_{3}(\mathrm{Den})+f_{4}(\mathrm{NEwind})$ & $5.38(12,17)$ & 0.0009 & 0.79 & 133.88 & 70.02 \\
\hline$R_{t}=f_{1}\left(N_{t-1}\right)+f_{2}(\mathrm{NAO})+f_{3}(\mathrm{Temp})+f_{4}(\mathrm{SWwind})$ & $5.15(12,17)$ & 0.0012 & 0.78 & 134.93 & 83.73 \\
\hline$R_{t}=f_{1}\left(N_{t-1}\right)+f_{2}(\mathrm{NAO})+f_{3}(\mathrm{Den})+f_{4}(\mathrm{SEwind})$ & $5.13(12,17)$ & 0.0012 & 0.78 & 135.00 & 97.51 \\
\hline$R_{t}=f_{1}\left(N_{t-1}\right)+f_{2}(\mathrm{NAO})+f_{3}(\mathrm{Den})+f_{4}(\mathrm{NWwind})$ & $5.09(12,17)$ & 0.0013 & 0.78 & 135.19 & 115.48 \\
\hline \multicolumn{6}{|l|}{ Ceratium tripos models } \\
\hline $\begin{aligned} R_{t}= & f_{1}\left(N_{t-1}\right)+f_{2}(\text { Temp })+f_{3}\left(N O_{3}\right)+f_{4}(N W w i n d)+ \\
& f_{5}(\text { NEwind })+f_{6}(\text { SEwind })+f_{7}(\text { NAO })\end{aligned}$ & $12.92(25,37)$ & $<0.00001$ & 0.90 & 205.44 & 0.00 \\
\hline$R_{t}=f_{1}\left(N_{t-1}\right)+f_{2}($ Temp $)+f_{3}($ NWwind $)+f_{4}($ SEwind $)$ & $10.33(12,50)$ & $<0.00001$ & 0.71 & 216.36 & 10.92 \\
\hline$R_{t}=f_{1}\left(N_{t-1}\right)+f_{2}($ Temp $)+f_{3}(\mathrm{NWwind})+f_{4}(\mathrm{SEwind})+f_{5}\left(\mathrm{NO}_{3}\right)$ & $9.78(15,47)$ & $<0.00001$ & 0.75 & 218.12 & 12.66 \\
\hline$R_{t}=f_{1}\left(N_{t-1}\right)+f_{2}(\mathrm{NAO})+f_{3}(\mathrm{Temp})+f_{4}(\mathrm{NWwind})$ & $9.22(12,50)$ & $<0.00001$ & 0.70 & 218.15 & 14.45 \\
\hline$R_{t}=f_{1}\left(N_{t-1}\right)+f_{2}(\mathrm{NAO})+f_{3}(\mathrm{Temp})+f_{4}(\mathrm{SEwind})$ & $9.69(12,50)$ & $<0.00001$ & 0.69 & 219.20 & 17.29 \\
\hline$R_{t}=f_{1}\left(N_{t-1}\right)+f_{2}(\mathrm{NAO})+f_{3}(\mathrm{Temp})+f_{4}(\mathrm{NEwind})$ & $8.22(12,50)$ & $<0.00001$ & 0.66 & 226.25 & 27.18 \\
\hline$R_{t}=f_{1}\left(N_{t-1}\right)+f_{2}(\mathrm{Temp})+f_{3}$ (NWwind) $+f_{4}($ SEwind $)+f_{5}\left(\mathrm{PO}_{4}\right)$ & $8.01(15,47)$ & $<0.00001$ & 0.72 & 227.00 & 37.82 \\
\hline$R_{t}=f_{1}\left(N_{t-1}\right)+f_{2}(\mathrm{NAO})+f_{3}(\mathrm{Temp})+f_{4}(\mathrm{SWwind})$ & $7.80(12,50)$ & $<0.00001$ & 0.65 & 228.42 & 49.88 \\
\hline \multicolumn{6}{|l|}{ Skeletonema costatum models } \\
\hline $\begin{aligned} R_{t}= & f_{1}\left(N_{t-1}\right)+f_{2}\left(\mathrm{NO}_{3}\right)+f_{3}(\mathrm{Sal})+f_{4}(\text { Temp })+ \\
& f_{5}(\text { SWwind })+f_{6}(\mathrm{NEwind})\end{aligned}$ & $11.11(16,6)$ & 0.0035 & 0.97 & 99.73 & 0.00 \\
\hline$R_{t}=f_{1}\left(N_{t-1}\right)+f_{2}\left(\mathrm{NO}_{3}\right)+f_{3}(\mathrm{Sal})+f_{4}(\mathrm{Den})+f_{5}(\mathrm{SWwind})$ & $9.36(15,7)$ & 0.0031 & 0.95 & 105.21 & 5.48 \\
\hline$R_{t}=f_{1}\left(N_{t-1}\right)+f_{2}\left(\mathrm{NO}_{3}\right)+f_{3}(\mathrm{Sal})+f_{4}($ SWwind $)$ & $8.65(12,10)$ & 0.0009 & 0.91 & 109.97 & 10.24 \\
\hline$R_{t}=f_{1}\left(N_{t-1}\right)+f_{2}\left(\mathrm{NO}_{3}\right)+f_{3}(\mathrm{Den})+f_{4}(\mathrm{SWwind})$ & $8.51(12,10)$ & 0.00096 & 0.91 & 110.31 & 15.39 \\
\hline$R_{t}=f_{1}\left(N_{t-1}\right)+f_{2}\left(\mathrm{NO}_{3}\right)+f_{3}(\mathrm{Sal})+f_{4}(\mathrm{NWwind})$ & $4.54(12,10)$ & 0.011 & 0.84 & 123.05 & 33.23 \\
\hline$R_{t}=f_{1}\left(N_{t-1}\right)+f_{2}\left(\mathrm{NO}_{3}\right)+f_{3}(\mathrm{Sal})+f_{4}$ (NEwind) & $4.10(12,10)$ & 0.016 & 0.83 & 124.98 & 53.00 \\
\hline$R_{t}=f_{1}\left(N_{t-1}\right)+f_{2}\left(\mathrm{NO}_{3}\right)+f_{3}(\mathrm{Sal})+f_{4}($ SEwind $)$ & $3.08(12,10)$ & 0.040 & 0.79 & 130.32 & 78.11 \\
\hline$R_{t}=f_{1}\left(N_{t-1}\right)+f_{2}\left(\mathrm{NO}_{3}\right)+f_{3}(\mathrm{Temp})+f_{4}(\mathrm{SWwind})$ & $2.95(12,10)$ & 0.048 & 0.78 & 131.09 & 103.99 \\
\hline
\end{tabular}

that may be captured using simple and general population dynamics models. In particular, phytoplankton fluctuations appear to be represented by a sort of switch-on/switch-off dynamic related to the withinyear seasonal forcing. When we analyzed the non-zero data in the phytoplankton fluctuations, the 3 phytoplankton populations showed a negative first-order feedback (direct density-dependence), suggesting that a biological process such as intra-specific competition represents a basic principle underlying the fluctuations of abundance in these species. In particular, the 3 species showed almost log-linear densitydependencies (Gompertz model), and intra-specific competition could be an important ecological force in these systems. However, as pointed out by Chesson \& Huntly (1997), fluctuations in environmental and weather conditions can create spatial and temporal ecological niche opportunities that can favor species coexistence. Looking at the results, it seems that nitrate could be regarded as a limiting nutrient in combination with fluctuations in temperature, NAO and associated wind conditions. The models also suggest that the species coexistence and fluctuating environmental conditions deviate from the common assumption that the association between species and abiotic conditions are always linear and additive (Chesson \& Huntly 1997), and also that since phytoplankton compete for a handful of resources, their dynamics may be complex and difficult to predict (Huisman \& Weissing 1999). The 2 dinoflagellate species showed some interesting differences; while Ceratium furca showed less influence of exogenous variables, C. tripos appeared to 
Table 3. Coefficients of the GAM models selected for each species. Smooth terms are represented using penalized regression splines with smoothing parameters selected by GCV (generalized cross validation) or by regression splines with fixed degrees of freedom (mixtures of the 2 are permitted). Parametric coefficients represent the linear terms in each model, edf are the estimated degrees of freedom of the smooth terms using cubic splines. Model notations are: $\mathrm{CF}=$ Ceratium furca density; $\mathrm{CT}=$ Ceratium tripos density; $\mathrm{SC}=$ Skeletonema costatum density; NAO = North Atlantic Oscillation index; $\mathrm{NO}_{3}=$ nitrate $\mathrm{PO}_{4}=$ phosphate $\mathrm{Chl}=\operatorname{chl} a_{i}$ Temp $=$ temperature $;$ Sal $=$ salinity; Den $=$ density of seawater; SEwind $=$ southeast wind; NEwind $=$ northeast wind; SWwind = southwest wind and NWwind = northwest wind. The appropriate smoothness for each applicable model term was selected using GCV. We initialized the analyses using splines with 7 df. s: splines

\begin{tabular}{|c|c|c|c|c|}
\hline \multicolumn{5}{|c|}{ Ceratium furca } \\
\hline & Estimate & $\mathrm{SE}$ & $t$ ratio & $\operatorname{Pr}(>|t|)$ \\
\hline Constant & -0.300 & 0.21 & -1.41 & 0.18 \\
\hline \multicolumn{5}{|c|}{ Approximate significance of smooth terms } \\
\hline & edf & $\chi^{2}$ & \multicolumn{2}{|c|}{$\mathrm{p}$-value } \\
\hline $\mathrm{s}(\log [\mathrm{CF}])$ & 3.99 & 183.58 & \multicolumn{2}{|c|}{$<0.00001$} \\
\hline s(Den) & 5.38 & 52.48 & \multicolumn{2}{|c|}{$<0.00001$} \\
\hline $\mathrm{s}(\mathrm{NAO})$ & 4.58 & 74.69 & \multicolumn{2}{|c|}{$<0.00001$} \\
\hline s(NEwind) & 3.82 & 19.64 & \multicolumn{2}{|c|}{0.0006} \\
\hline
\end{tabular}

\section{Ceratium tripos}

Parametric coefficients

\begin{tabular}{ccccc} 
& Estimate & SE & $t$ ratio & $\operatorname{Pr}(>|t|)$ \\
\hline Intercept & -0.55 & 0.24 & -2.33 & 0.026
\end{tabular}

Approximate significance of smooth terms

\begin{tabular}{lcrc} 
& edf & \multicolumn{1}{c}{$\chi^{2}$} & p-value \\
\hline s(log[CT]) & 3.35 & 121.85 & $<0.00001$ \\
s(Temp) & 2.37 & 29.44 & $<0.00001$ \\
s(NEwind) & 5.78 & 34.09 & $<0.00001$ \\
s(NAO) & 4.12 & 27.47 & $<0.00001$ \\
s(NO $\left.{ }_{3}\right)$ & 5.92 & 25.53 & 0.0002 \\
s(SEwind) & 4.03 & 29.85 & $<0.00001$ \\
s(Sal) & 4.02 & 18.01 & 0.0011
\end{tabular}

\section{Skeletonema costatum}

Parametric coefficients

\begin{tabular}{lrrrr} 
& Estimate & $\mathrm{SE}$ & $t$ ratio & $\operatorname{Pr}(>|t|)$ \\
\hline Intercept & 18.75 & 3.62 & 5.75 & 0.00043 \\
$\mathrm{NO}_{3}$ & 0.98 & 0.13 & 7.66 & $<0.00001$ \\
$\mathrm{Sal}$ & -0.93 & 0.14 & -6.82 & 0.0001
\end{tabular}

Approximate significance of smooth terms

\begin{tabular}{lccc} 
& edf & $\chi^{2}$ & p-value \\
\hline s(log[SC]) & 3.10 & 94.52 & $<0.00001$ \\
s(SWwind) & 3.22 & 29.86 & $<0.00001$ \\
s(Temp) & 3.51 & 27.92 & $<0.00001$ \\
s(NEwind) & 2.25 & 8.89 & 0.015 \\
\hline
\end{tabular}

be largely influenced by exogenous forces. However, the latter species is more persistent at our study site.

On the other hand, our results are consistent with the role that physical and environmental processes play in determining phytoplankton fluctuations (Smayda 2002). All species showed effects of different exogenous variables. In particular, our results may suggest that the NAO and nitrates positively affect these dinoflagellate species, whereas salinity/density, northeast and southeast wind intensity have negative effects, suggesting that algal blooms of Ceratium furca and $C$. tripos are related to these particular environmental conditions. For example, Margalef et al. (1979) and Smayda \& Reynolds (2001) showed that favorable conditions for dinoflagellate growth include high irradiance, low turbulence and high nutrient concentration. However, regarding turbulence, Sullivan \& Swift (2003) showed that contrary to the paradigm in phytoplankton ecology, stating that dinoflagellates are always affected negatively by turbulence, when considering different small-scale turbulence regimes the response is species specific and in some cases can be contradictory. Interestingly, C. furca and C. tripos both showed positive responses to the NAO in the study area, as previously reported by Belgrano et al. (1999) for 3 species of Dynophysis dinoflagellates, showing strong correlations with NAO $\left(\mathrm{R}^{2}=0.9\right)$ and temperature $\left(\mathrm{R}^{2}=0.66\right)$. This reflects the increase in sea surface temperature associated with a positive NAO phase at the study site (Belgrano et al. 1999) and in the North Sea and adjacent areas (Reid et al. 1998, Ottersen et al. 2001).

In contrast, the exogenous forces influencing the dynamics of the diatom species Skeletonema costatum showed some interesting differences and similarities with the population dynamics of dinoflagellates. For example, in the same vein as the 2 Ceratium species, the diatom showed positive effects of nutrient $\left(\mathrm{NO}_{3}\right)$ concentration and temperature, and negative effects of high salinity. In particular temperature plays an important role in the aggregations of $S$. costatum cells, resulting in higher sinking rates, thus reflecting changes in the flux rate of carbon from the euphotic zone to deeper waters (Thorton \& Thake 1998). However, in contrast with dinoflagellates, $S$. costatum appears to benefit from high northeast wind intensity and intermediate southwest wind intensity. The role of nutrients and temperature suggest the importance of resource limitation as well as a direct link to metabolic rate, and this in turn may be related to higher production and faster turnover or generation times. The negative effects of wind intensity on $C$. furca and C. tripos reveal that dinoflagellate growth rate increases during a period of low mixing (low wind intensity); in contrast, the diatom appears to benefit from high or intermedi- 

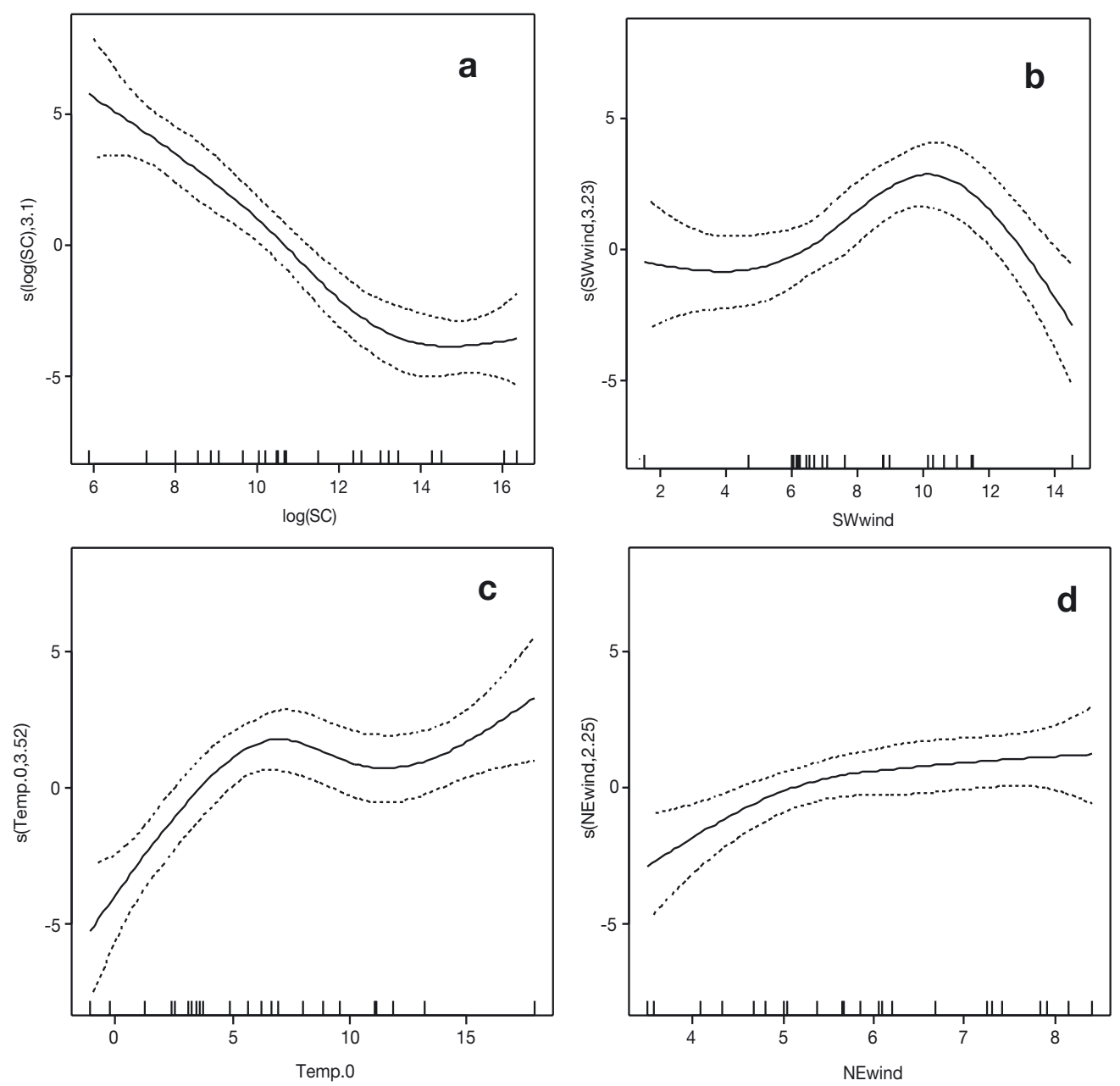

Fig. 6. Skeletonema costatum. See legend to Fig. 4 for details. S. costatum density (SC); southwest wind (SWwind); temperature (Temp.0); and northeast wind (NEwind) are shown

ate wind intensity, which represents periods of high mixing in the column of water. These changes in the abiotic condition along the Swedish west coast have been observed before (Lindahl et al. 1998), and suggest that transport of nutrients associated with stronger southwest winds from the Kattegat area, which are directly linked to a positive NAO scenario, may be related to large phytoplankton blooms, as was observed for $S$. costatum in 1987.

As suggested by Andereis \& Beisner (2000), it is the interaction of abiotic and biotic factors and stochasticity that determines fluctuations at the species level, but this also allows species coexistence on common exploitable and fluctuating resources. The amplitude of this transfer function relating species to environmental fluctuations can increase at longer time scales, providing an indication of the integrative properties of cellular physiology. A reduction in vertical mixing from a few days to a period of ca. 2 wk may reduce the vertical mixing, leading to increased biomass (Harris 1986) in relation to the variance in the physical structure. The resulting dynamics may be reflected in the non- linear relations found between species abundance and exogenous factors.

Single-species logistic models represent an appropriate general theoretical framework for understanding natural fluctuations in population dynamics studies. Moreover, conceptual elements, such as feedback structure and exogenous forces (climate), provide the basis for understanding the factors that may trigger phytoplankton bloom events (Huppert et al. 2002), including potentially toxic species (Belgrano et al. 1999). Phytoplankton population dynamics need to be considered to obtain a macroecological perspective of marine ecosystem dynamics (Brown 1999, Belgrano \& Brown 2002). Ultimately, the goal is to link long-term and large-scale climatic fluctuations to species dynamics, thus resulting in the role of 'emergence' from pelagic organisms to pelagic organization, as proposed by Reynolds (2001).

Acknowledgements. A.B. acknowledges the support of an NSF Biocomplexity Grant (DEB-0083422). M.L. acknowledges financial support from FONDAP-FONDECYT Grant 1501-0001 (Program 2). N.C.S. acknowledges the Norwegian science council support through the EcoClim-project. 


\section{LITERATURE CITED}

Anderies JM, Beisner B (2000) Fluctuating environments and phytoplankton community structure: a stochastic model. Am Nat 155:556-569

Armstrong RA, McGehee R (1976) Coexistence of two competitors on one resource. J Theor Biol 56:499-502

Belgrano A, Brown JH (2002) Oceans under the macroscope. Nature 419:128-129

Belgrano A, Lindahl O, Hernroth B (1999) North Atlantic Oscillation (NAO) primary productivity and toxic phytoplankton in the Gullmar Fjord, Sweden (1985-1996). Proc R Soc Lond B 266:425-430

Belgrano A, Malmgren B, Lindahl O (2001) The use of artificial neural network for predicting primary productivity. J Plankton Res 23:651-658

Berryman AA (1981) Population systems: a general introduction. Plenum Press, New York

Berryman AA (1999) Principles of population dynamics and their applications. Stanley Thornes Publishers, Cheltenham

Bjørnstad ON, Grenfell BT (2001) Noisy clockwork: time series analyses of population fluctuations of animals. Science 293:638-643

Bjørnstad ON, Stenseth, NC, Falck W (1998) A geographical gradient in small rodent density fluctuations: a statistical modeling approach. Proc R Soc Lond B 262:127-133

Bjørnstad ON, Fromentin JM, Stenseth, NC, Gjøsæter J (1999) A new test for density-dependent survival: the case of coastal cod populations. Ecology 80:1278-1288

Brown JH (1999) Macroecology: progress and prospect. Oikos $87: 3-14$

Chesson P (2000) Mechanisms of maintenance of species diversity. Annu Rev Ecol Syst 31:343-366

Chesson P, Huntly N (1997) The roles of harsh and fluctuating conditions in the dynamics of ecological communities. Am Nat 150:519-533

Green PJ, Silvermann BW (1994) Nonparametric regression and generalized linear models - a roughness penalty approach. Chapman \& Hall, London

Hanski I (1999) Metapopulation ecology. Oxford University Press, Oxford

Harris GP (1986) Phytoplankton ecology. Chapman \& Hall, London

Hastie T, Tibshirani R (1990) Generalized additive model. Chapman \& Hall, London

HELCOM (1998) Guidelines for the Baltic Monitoring Programme for the third stage. Balt Sea Environ Proc 27:1-49

Huisman J, Weissing FJ (1999) Biodiversity of plankton by species oscillations and chaos. Nature 402:407-410

Huppert A, Blasius B, Stone L (2002) A model of phytoplankton blooms. Am Nat 159:156-171

Hurrell JW (1995) Decadal trends in the North Atlantic Oscillation: regional temperatures and precipitation. Science 269:676-679

Kristoffersen AB, Lingjærde, OC, Stenseth NC, Shimada M (2001) Non-parametric modelling of non-linear density dependence: a three-species host-parasitoid system. J Anim Ecol 70:808-819

Lindahl O, Belgrano A, Davidsson L, Hernroth B (1998) Primary production, climatic oscillations, and physicochemical processes: the Gullmar Fjord time-series data set (1985-1996). ICES J Mar Sci 55:723-729

Litchman E, Klausmeier CA (2001) Competition of phytoplankton under fluctuating light. Am Nat 157:170-187

Editorial responsibility: Otto Kinne (Editor),

Oldendorf/Luhe, Germany
Margalef R, Estrada M, Blasco D (1979) Functional morphology of organisms involved in red tides, as adapted to decay turbulence. In: Taylor DL, Seliger HH (eds) Toxic dinoflagellate blooms. Elsevier, New York, p 505

Merritt JF, Lima M, Bozinovic F (2001) Seasonal regulation in fluctuating small mammal populations: feedback structure and climate. Oikos 94:505-514

Murdoch WW, Kendall BE, Nisbet RM, Briggs CJ, McCauley E, Bosler R (2002) Single-species models for many-species food webs. Nature 417:542-543

Murúa R, González L, Lima M (2003) Population dynamics of rice rats (a Hantavirus reservoir) in southern Chile: feedback structure and non-linear effects of climatic Oscillations. Oikos 102:137-145

Mysterud A, Stenseth NC, Yoccoz NG, Laangvatn R, Steinheim G (2001) Nonlinear effects of large-scale climatic variability on wild and domestic herbivores. Nature 410: 1096-1099

Ottersen G, Planque B, Belgrano A, Post E, Reid PC, Stenseth NC (2001) Ecological effects of the North Atlantic Oscillation. Oecologia 128:1-14

Reid PC, Edwards M, Hunt HG, Werner J (1998) Phytoplankton change in the North Atlantic. Nature 391:546

Reynolds CS (2001) Emergence in pelagic communities. Sci Mar 65:5-30

Ricker WE (1954) Stock and recruitment. J Fish Res Board Can 11:559-623

Royama T (1992) Analytical population dynamics. Chapman \& Hall, London

Sinclair AER, Krebs CJ (2002) Complex numerical responses to top-down and bottom-up processes in vertebrate populations. Proc R Soc Lond B 357:1221-1231

Smayda TJ (2002) Adaptive ecology, growth strategies, and the global bloom expansion of dinoflagellates. J Oceanogr 58:281-294

Smayda TJ, Reynolds CS (2001) Community assembly in marine phytoplankton: application of recent models to harmful dinoflagellate blooms. J Plankton Res 23:447-461

S-Plus (2000) Guide to statistics, Vol 1. MathSoft, Seattle

Stenseth NC, Falck W, Bjørnstad ON, Krebs CJ (1997) Population regulation in snowshoe hare and Canadian lynx: asymmetric food web configuration between hare and lynx. Proc Natl Acad Sci USA 94:5147-5152

Stenseth NC, Mysterud A, Ottersen G, Hurrell JW, Chan KS, Lima M (2002) Ecological effects of climate fluctuations. Science 297:1292-1296

Stenseth NC, Ottersen G, Hurrell JW, Mysterud A, Lima M, Chan, KS, Yoccoz, NG, Adlandsvik B (2003) Studying climate effects on ecology through the use of climate indices: the North Atlantic Oscillation, El Niño Southern Oscillation and beyond. Proc R Soc Lond Ser B 270:2087-2096

Sullivan JM, Swift E (2003) Effects of small-scale turbulence on net growth rate and size of ten species of marine dinoflagellates. J Phycol 39:83-94

Thorton DCO, Thake B (1998) Effect of temperature on the aggregation of Skeletonema costatum (Bacillariophyceae) and the implication for carbon flux in coastal waters. Mar Ecol Prog Ser 174:223-231

Turchin P (1995) Population regulation: old arguments and a new synthesis. In: Capuccino N, Price PW (eds) Population dynamics: new approaches and synthesis. Academic Press, San Diego, p 19-37

Wood SN (2001) MGCV, GAMs and generalized ridge regression for R. R News 1:20-25

Submitted: April 16, 2003; Accepted: February 5, 2004

Proofs received from author(s): April 22, 2004 